\title{
Marrow involvement with T cell lymphoma initially presenting as abnormal myelopoiesis
}

\author{
MJ AUGER, JRG NASH*, MJ MACKIE \\ From the University Departments of Haematology and ${ }^{*}$ Histopathology, Royal Liverpool Hospital, Liverpool
}

SUMMARY Three cases of $\mathrm{T}$ cell lymphoma affecting the marrow, in which initial bone marrow appearances were misleading, occurred. In each case the initial clinical presentation was related to cytopenia, but the marrow abnormalities at this time suggested an abnormal myeloid proliferative state, with no evidence of a malignant lymphoid proliferation. Later in the course of the disease, however, the characteristic pattern of marrow infiltration by mature post -thymic $T$ cells became evident. The consequent delay (two to 36 months) in diagnosis was noted.

T cell lymphomas comprise about $20 \%$ of nonHodgkin's lymphomas in adults (unpublished observations). They are often disseminated and carry a poor prognosis. Bone marrow infiltration at presentation is a well recognised feature of this type of lymphoma. ${ }^{1}$ We examined the evolution of bone marrow aspirate and biopsy appearances in six consecutive patients with $\mathrm{T}$ cell lymphoma with spread to the marrow, who presented to a teaching hospital. In three of these six patients the appearances on bone marrow biopsy at presentation were of extensive infiltration of the marrow by $\mathrm{T}$ lymphocytes, but in the remaining three patients the appearances were initially atypical and only later did the characteristic features of marrow infiltration by lymphoma appear. We describe these three patients in more detail.

\section{Case reports}

CASE 1

A 61 year old woman presented with small painless cervical lymphadenopathy and a facial rash, but no constitutional symptoms. She had cytopenia (haemoglobin $9.7 \mathrm{~g} / \mathrm{dl}$; white cell count $2.0 \times 10^{9} / \mathrm{l}$; platelets $\left.205 \times 10^{9} / 1\right)$. A bone marrow aspirate and biopsy showed features of refractory anaemia with excess blast cells, which, morphologically and cytochemically, were myeloblasts (Fig. 1).

She remained well initially with symptomatic treatment alone, but later developed enlarging generalised lymphadenopathy and splenomegaly. A subsequent lymph node biopsy and biopsy of her skin rash showed features of a $\mathrm{T}$ cell lymphoma. The lymph node architecture was effaced, with only small col-

Accepted for publication 23 October 1985 lections of lymphocytes remaining. The bulk of the node was replaced by a vaguely nodular proliferation composed of a mixture of cell types: the predominant cells were large "transformed" pale lymphocytes with convoluted nuclei and small nucleoli. Epithelioid macrophages were interspersed among these, and blood vessels were unusually common and prominent. Immunoenzymatic staining subsequently confirmed the large pale lymphocytes as $\mathrm{T}$ helper cells. A bone marrow biopsy supported the diagnosis, showing heavy infiltration by a mixed population of small and large $T$ helper cells, many of which showed convoluted nuclei (Fig. 2). Very strong staining for $\mathrm{T}$ helper antigen was present (Fig. 3), moderately strong Pan-T and HLA-DR staining; a small number of cells stained for $T$ suppressor antigen. There was also erythrodysplasia and considerably increased numbers of plasma cells. The population of plasma cells was polyclonal for light and heavy chains.

Despite chemotherapy her general condition deteriorated and she died. Necropsy tissue samples showed total replacement of many lymph nodes by $\mathrm{T}$ helper lymphoma.

\section{CASE 2}

A 47 year old woman was admitted with malaise, weight loss, and sweating. She had a low grade fever, generalised tender lymphadenopathy, but no hepatosplenomegaly. She had pancytopenia (haemoglobin $5.9 \mathrm{~g} / \mathrm{dl}$; white cell count $2.4 \times 10^{9} / 1$; platelets $57 \times$ $\left.10^{9} / 1\right)$ and a few atypical lymphocytes on the peripheral blood film. A bone marrow aspiration resulted in a dry tap, but the biopsy was hypercellular with greatly increased numbers of atypical megakaryocytes, as well as a reduced and left shifted 


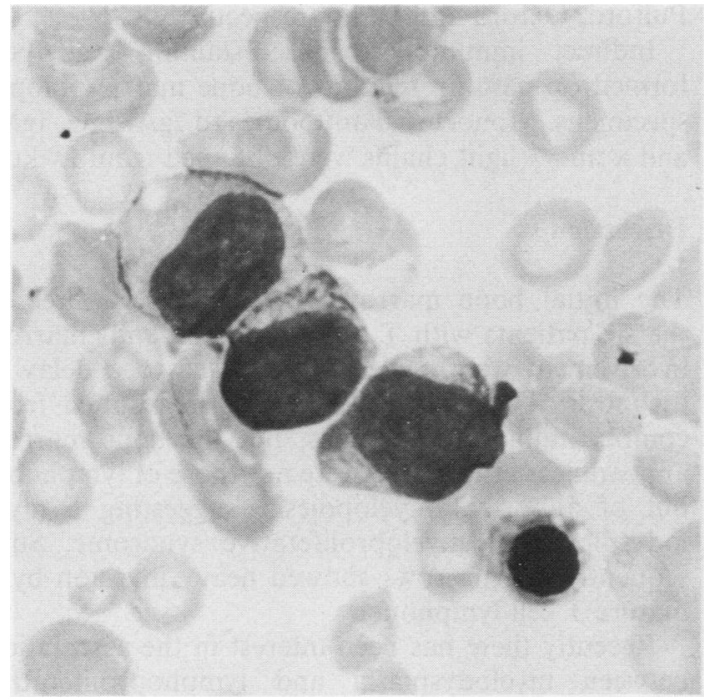

Fig. 1 Bone marrow aspirate from case 1 showing features of refractory anaemia with excess myeloblasts. $\times 1500$. (May-Grünwald-Giemsa stain.)

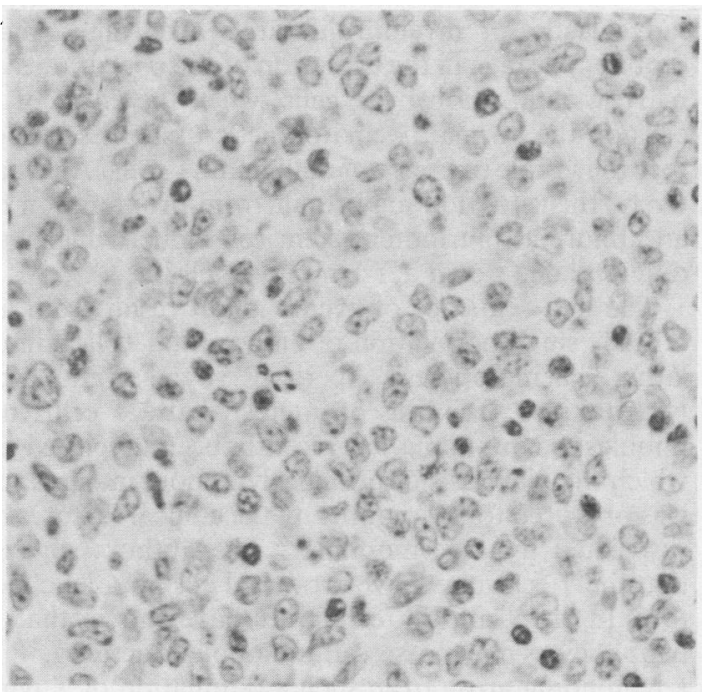

Fig. 2 Bone marrow biopsy from case 1 with heavy infiltrate of T cells. (Haematoxylin and eosin.) $\times 375$.

myeloid series and erythrodysplasia. There was no increased lymphoid population (Fig. 4). Axillary lymph node biopsy was performed. The node showed replacement of its entire structure by paracortical tissue with many prominent blood vessels. Macrophages were present in increased numbers. The lymphoid cell population was composed of small lymphocytes,

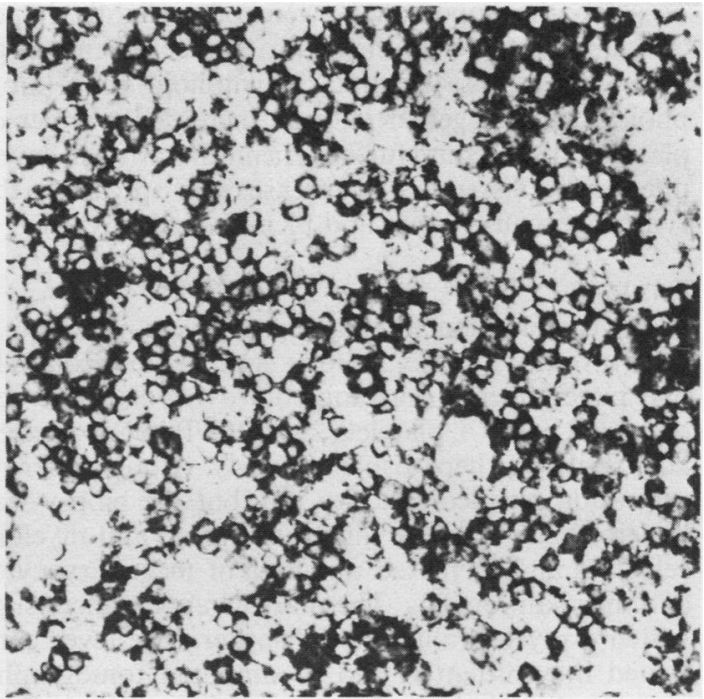

Fig. 3 Lymph node biopsy from case 1 stained immunoenzymatically to show Thelper lymphocytes. $\times 375$.

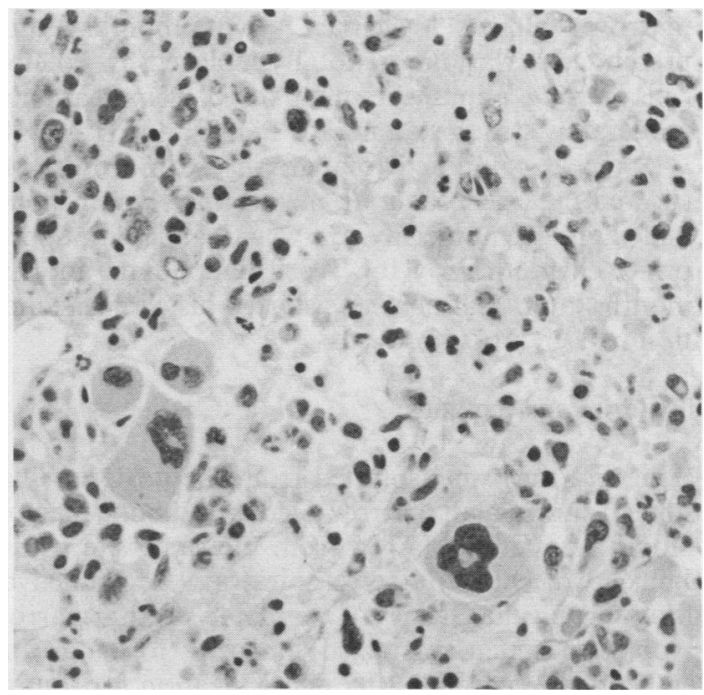

Fig. 4 Bone marrow biopsy from case 2 showing erythrodysplasia, left shifted myeloid series, and increased plasma cells, but no lymphoid infiltrate. (Haematoxylin and eosin.) $\times 375$.

many with irregular nuclei, large pleomorphic lymphocytes with pale nuclei and prominent nucleoli, resembling immunoblasts, and forms intermediate between these two types. These appearances strongly suggested T cell lymphoma. She was treated with two courses of chemotherapy, and a bone marrow biopsy was repeated two months after presentation. On this 
occasion the appearances were of a slightly hypocellular marrow, with the majority of cells being large transformed post -thymic T lymphoid cells (morphologically), together with an increased number of plasma cells. Despite further chemotherapy she developed more disseminated disease with spread to the central nervous system and pleura, and she died.

\section{CASE 3}

A 21 year old man complained of fevers, weight loss of two stones over six months, and a sore throat. He had pancytopenia (haemoglobin $9.4 \mathrm{~g} / \mathrm{dl}$; white cell count $0.3 \times 10^{9} / 1$; platelets $29 \times 10^{9} / 1$ ) but no lymphadenopathy or hepatosplenomegaly. A bone marrow aspiration resulted in a dry tap, but the biopsy was hypercellular with left shifted erythroid and myeloid cell lines and increased numbers of megakaryocytes and megakaryoblasts. The marrow appearances suggested a myeloproliferative disorder. The fever continued intermittently, and a computed tomography scan of the whole body was entirely normal. Two further bone marrow biopsies were similar in appearances but on one of these there was also a considerably increased number of macrophages. A fourth marrow biopsy specimen two months after presentation was almost totally replaced by $\mathrm{T}$ helper cells (strong immunostaining for $T$ helper antigen; moderately strong staining for Pan-T and HLA-DR).

A repeat computed tomography scan at this time showed enlarged superior mediastinal lymph nodes and slight splenomegaly. He was treated with appropriate chemotherapy for $\mathrm{T}$ cell lymphoma, and five months after treatment was started his clinical condition had greatly improved.

\section{Material and methods}

Bone marrow was aspirated from the posterior iliac spine using a Salah marrow needle, and bone marrow biopsy was also obtained from the same site with a Jamshidi needle. Marrow aspirates were stained by May-Grunwald-Giemsa stain. Half of the marrow biopsy specimen was fixed in acetic formalin and embedded in paraffin after decalcification for routine histology. The resulting sections were stained with haematoxylin and eosin, Giemsa, and for reticulin. The remaining half of the biopsy specimen was immersed in a $50 \%$ gum sucrose solution and snap frozen in liquid nitrogen. Frozen sections $(6 \mu \mathrm{m})$ were cut and dried on to a slide at room temperature. Immunoenzymatic staining was carried out by the alkaline phosphatase-antialkaline phosphatase (APAAP) technique as described by Cordell et al. ${ }^{2}$ Monoclonal antibodies to IgM, IgD, Pan B, Pan T, T helper, T suppressor, HLA-DR, CALLA, and macrophage antigens were provided by $\mathrm{Dr}$ Mason and $\mathrm{Dr}$
Pulford, Oxford and Dako, respectively.

Indirect immunoperoxidase staining was performed on paraffin sections of bone marrow biopsy specimens. Monoclonal antibodies to IgA, IgG, IgM, and $\kappa$ and $\lambda$ light chains were obtained from Dako.

\section{Discussion}

The initial bone marrow appearances in three of the six patients with $\mathrm{T}$ cell lymphoma and marrow involvement were misleading and led to a delay in diagnosis. Their clinical presentation resulted from complications of cytopenias, but the bone marrow appearances at this time were not those of lymphoma but of abnormal myelopoiesis, suggesting a myelodysplastic or myeloproliferative syndrome. Subsequently, all marrows showed heavy invasion by a mature $\mathrm{T}$ cell lymphoma.

Recently there has been interest in the association between myelodysplasia and lymphoproliferative disorders. In one study of 160 patients with myelodysplastic syndromes two were found to have coexistent $\mathrm{T}$ cell lymphoma. ${ }^{3}$

We believe coexistent $T$ cell lymphoma and myelodysplastic, or myeloproliferative syndromes, may represent a stage in the evolution of the appearance of marrow infiltration by $T$ cells, when the effect of $T$ cells on the normal haematopoietic tissue is seen before the visible presence of malignant $T$ cells. Alternatively, this situation may result from proliferation of an abnormal pluripotent stem cell clone, which has differentiated down a $\mathrm{T}$ lymphoid cell line.

The first sequence of events might result from an initially small population of malignant $T$ cells stimulating haematopoiesis, perhaps by secretion of lymphokines. It is thus of interest that a $\mathrm{T}$ cell lymphoblastic lymphoma has recently been described, in which the diagnosis of primary lymphoid malignancy was obscured for 13 months by the clinical features of associated hypereosinophilia. ${ }^{4}$ The authors suggest that the $\mathrm{T}$ cells may have produced eosinopoietic factors. In vitro culture techniques have shown that $T$ lymphocytes may possess granulopoietic activity. ${ }^{56}$ If a lymphoma arose from such a population of $T$ lymphocytes then features of a myelodysplastic or myeloproliferative syndrome might be associated. Later, as the clone of malignant $T$ cells expands, the characteristic picture of lymphoma would become obvious, as happened in our three patients.

The secretarial assistance of Miss H R Dimmock is greatly appreciated.

\section{References}

${ }^{1}$ Palutke M, Tabaczka P, Weise RW, et al. T-cell lymphomas of large cell type. Cancer 1980;46:87-101. 
${ }^{2}$ Cordell JL, Falini Abdulaziz Z, Woolston R-E, Mason DY Immunoenzymatic labelling of monoclonal antibodies using immune complexes of alkaline phosphatase and monoclonal anti-alkaline phosphatase (APAAP) complexes. Histochem Cytochem J 1984;32:219-29.

${ }^{3}$ Copplestone JA, Mufti GJ, Oscier DG, Hamblin TJ. Co-existent myelodysplasia in lymphoproliferative disorders. (Abstract) Proceedings of the British Society for Haematology. 26th Annual Meeting 1985, Oxford: Blackwell Scientific Publications (in press).

${ }^{4}$ Keiden AJ, Catovsky D, Tavares de Castro J, Spry CJF. Hypereosinophilic syndrome preceding T-cell lymphoblastic lymphoma. Clin Lab Haematol 1985;7:83-8.
${ }^{5}$ Howard M, Burgess A, McPhee D, Metcalf D. T-cell hybridoma secreting hemopoietic regulatory molecules: granulocytemacrophage and eosinophil colony-stimulating factors. Cell 1979;18:993-9.

${ }^{6}$ Ruscetti FW, Cypess RH, Chervenick PA. Specific release of neutrophilic-stimulating factors from sensitised lymphocytes. Blood 1976;47:757-65.

Requests for reprints to: Dr MJ Auger, Department of Haematology, Royal Liverpool Hospital, Prescot Street, Liverpool L7 8XP, England. 